\title{
The Italian productivity slowdown in a Real Business Cycle perspective*
}

\author{
Francesca Marino ${ }^{\dagger}$ \\ University of Bari "Aldo Moro"
}

This version: April 2013

\begin{abstract}
This paper investigates the structural relation between the italian weak macroeconomic performances and the productivity decline experienced over the last fifteen years, estimating a Dynamic Stochastic General Equilibrium (DSGE) model. Modifying Ireland and Schuh's (2008) two-sector RBC model in order to account for cointegration between consumption and investment, we interpret the unsatisfactory italian economic dynamics in light of a permanent negative shock to the component of productivity which is common across the consumption-good and the investment-good sector. In light of our results, the common view that the italian productivity problems involve only the Made in Italy sectors is only partially confirmed, since growth in the investmentgood sector relies on the counterbalancing properties of its transitory sector-specific productivity component. Moreover, the model indirectly stresses the importance of the intermediate-good productions in the observed productivity decline. The short and long-run implications of productivity dynamics for the consumption, investment and hours worked are also briefly discussed.
\end{abstract}

JEL classification: E32, O41

Keywords: Real Business Cycle model, italian productivity slowdown, structural approach

\section{Introduction}

The structural relationship between productivity dynamics and macroeconomic performances has been deeply investigated in the US literature. Indeed, as of the seminal paper

${ }^{*}$ I thank the participants to the Fifth Italian Congress of Econometrics and Empirical Economics (ICEEE 2013) in Genova for useful suggestions. Among others, I thank prof. Woitek and prof. Hoffman for their invaluable advice.

${ }^{\dagger}$ Corresponding author: francesca.marino@uniba.it 
by Kidland and Prescott (1982), the Dynamic Stochastic General Equilibrium (DSGE) approach has been widely exploited and refined in the analysis of both business cycle and long-run dynamics, giving new insights into phenomena like the marked US productivity slowdown in the 1970s, and its following great revival in the 1990s. For instance, in a Real Business Cycle (RBC) framework, Greenwood, Hercowitz and Krusell (1997; 2000) disentangle neutral from investment-specific technology, discussing how a change in the latter was responsible of the observed great productivity growth in the 1990s. Pakko (2002; 2005), introducing shocks to both the level and the growth rate of technology in Greenwood et al.'s (2000) model, interprets the productivity growth in the 1990s as a persistent acceleration of the technology trend started 10 years before. Following the lines of Whelan (2003), who gives Greenwood et al.'s (2000) model a two-sector interpretation, Ireland and Schuh (2008) estimate a two-sector Real Business Cycle (RBC) model for the US and relate the observed patterns of consumption and investment to divergent sectoral productivity dynamics. More recently, Justiniano, Primiceri and Tambalotti (2010, 2011) introduce investment-specific shocks in a New-Neoclassical Synthesis model of Business Cycle, with a number of nominal and real frictions, showing that the current recession can be explained by an investment-specific shock affecting the transformation of current savings into future capital input.

On the other side of the Atlantic, the nexus between the stagnation in productivity, recorded in the mid 1990s for almost all the old-Europe members, and the European disappointing long-run growth performances failed to be properly investigated in such a fully structural perspective, with very few exceptions (e.g., Ireland 2011 for the Euro Area). It is even more striking that this literature gap involves countries like Italy, that along with Spain, experienced the worst and most protracted slowdown of per capita output growth and whose dismal productivity performances impacted significantly on the average growth rate in the Union (van Ark et al. 2007). Indeed, the bulk of the existing conributions on the italian productivity slowdown focus on non-structural approaches, mainly growth accounting exercises (e.g. Daveri and Jona-Lasinio, 2005; Bassanetti et al. 2004) and supply-side oriented analysis (Sgherri, 2005; Aiello et al. 2011).

Though requiring many theoretical restrictions and lacking of flexibility, fully parameterized general equilibrium models have the advantage of providing a mapping between observable variables and structural shocks, and allow to predict both the short and longrun effects of productivity shocks to the key macroeconomic variables. Similar structural approaches would thus provide useful insights into the relation between the long-lasting italian productivity slowdown and its arising economic weakness - low competitiveness, economy's supply problems, wage moderation, weak domestic demand. The future economic prospects of the single member states matters for the stability of Europe as a whole; with respect to this, investigating the italian efficiency problems and its consequences on employment, consumption, output and investment is not a mere intellectual exercise, nor it has only national relevance.

In light of this premise, this paper estimates a DSGE model for Italy, linking the behav- 
iour of three macroeconomic variables - consumption, investment and hours worked - to its poor productivity performances. Exploiting a fully parameterized model, we provide a theoretical framework in order to predict the short and long-run effects of the observed productivity patterns on these key variable, and provide new insights on the existing empirical evidences and stylized facts on italian productivity.

The theoretical framework here exploited is a modification of the two sector-RBC model developed by Ireland and Schuh (2008). In the original model, the economy is decomposed into a consumption-good sector and an investment-good sector, while the dynamics of the system are driven by the level and growth rate components of shocks to preferences and sector-specific productivity. Since consumption and investment-good technology are driven by sector-specific stochastic processes, the main implication of a two sector model is that technology growth rate may be different across sectors and, most importantly, that consumption and investment - if non stationary - are not necessarily cointegrated (Ireland and Schuh, 2008). This accounts for the divergent behaviour of consumption and investment in the US, strikingly evident as of the beginning of the 1990s. Cointegration of consumption and investment is instead a direct consequence of the traditional one-sector RBC model as in King, Plosser and Rebelo (1988) with random-walk productivity, as discussed in King, Plosser, Stock and Watson (1991). In this one-sector framework, consumption and investment are driven by the same stochastic process in the long run.

Looking at the relation between consumption and investment for Italy (Figure 1a), it is quite evident that they tend to move together in the long run. In principle, this would require the presence of a single stochastic process for productivity, i.e. a single sector model. However, since consumption matches the marked drop of Total Factor Productivity (TFP), looking on a flatter path after 2000 (Figure 1b), while investment continues to stick to its long run trend, the different behaviour about the trend across these two variables suggests the possibility that sector-specific components are also involved, and these two sectors may have contributed differently to the observed economic decline. With respect to this, keeping the two sectors separated would allow to compute the contribution of both sector-specific and global factors, differently from a pure single-sector model, where only one productivity process is involved. This would be particularly interesting for Italy, since the consumptiongood sector partially encompasses the main "Made in Italy" industries, and represents the core of the manufacturing sector, traditionally considered as the main responsible of the italian decline (Daveri and Jona-Lasinio, 2005; Venturini, 2004).

Thus, we tranform Ireland and Schuh's (2008) pure two-sector model in a hybrid where the level-component of productivity - i.e. the one responsible for the short-run dynamics and temporary changes in growth and levels - can be different across sectors, while the growth component - responsible for productivity long run growth and permanent shifts - is the same. In general, the common-trend assumption is consistent with the idea that sectoral performances are affected by both idiosyncratic factors - like inputs or sectorspecific knowledge - and other common features - like infrastructures or global shocks. Note that constraining sectoral productivity growth component to be the same is different 
from assuming that productivity is cointegrated across sectors, as for instance in SchmittGrohe and Uribe (2011) and Park (2012), since cointegrated sectoral productivity does not necessarly imply that real consumption and investment are cointegrated.

Ireland and Schuh's (2008) model has a number of other appealing features. Indeed, it enriches the dynamics of the system, implying a time-series decomposition of shocks into level and growth-rate components; this is useful in order to interpret the observed slowdown as arising from transitory or rather permanent factors. Moreover, their model contains also non technical (preferences) disturbances, which act as general competitors of the technological shocks. As it will be clear later, preference shocks may take into account the effects of italian specific events - like the labour market reforms in the late 1990s and early 2000 s - on the long-run dynamics of hours worked.

The remainder of this paper is as follows: paragraph 2 introduces the model; paragraph 3 discusses the results of the estimates of the structural parameters, the smoothed estimates of sectoral productivity and the Impulse Response Functions (IRFs), also in light of the existing literature on italian productivity slowdown, while paragraph 4 concludes. Graphs and technical details on the methodology are in the Appendix.

\section{Model and Methodology}

Consider the expected utility function describing the preferences of the representative, infinitely-lived household,

$$
E_{0} \sum_{t=0}^{\infty} \beta^{t}\left[\ln \left(C_{t}-\gamma C_{t-1}\right)-\frac{\left(H_{c t}+H_{i t}\right)}{A_{t}}\right]
$$

where $C_{t}$ is denotes consumption and $H_{c t}$ and $H_{i t}$ are the hours worked, respectively, in the sector producing consumption and investment goods, at time $t . \beta$ is the discount factor and $\gamma$ the habit persistence parameter, both lying between 0 and 1 . The household's utility is logarithmic in consumption and linear in leisure. ${ }^{1}$ A shock to preferences $\left(A_{t}\right)$ is incorporated in the utility fuction: it affects the marginal rate of substitution between consumption and leisure so that, after a positive preference shock, consumption and hours worked both increase. Aggregate hours worked are defined as $H_{t}=H_{c t}+H_{i t}$.

The economy consists of two distinct sectors, producing respectively consumption $\left(C_{t}\right)$ and investment $\left(I_{c t}, I_{i t}\right)$ goods, according to the following Cobb-Douglas, stochastic technologies

$$
\left[1-\frac{\phi_{h c}}{2}\left(\frac{H_{c t}}{H_{c t-1}}-\eta_{c}\right)^{2}\right]\left[1-\frac{\phi_{k c}}{2}\left(\frac{I_{c t}}{K_{c t}}-\kappa_{c}\right)^{2}\right] K_{c t}^{\theta c}\left(Z_{c t} H_{c t}\right)^{1-\theta c} \geq C_{t}
$$

\footnotetext{
${ }^{1}$ Linearity in leisure is consistent with the view that the economy is compound by a large number of households, each including a potential employee who either works full time or not at all in each time (Hansen, 1988).
} 


$$
\left[1-\frac{\phi_{h i}}{2}\left(\frac{H_{i t}}{H_{i t-1}}-\eta_{i}\right)^{2}\right]\left[1-\frac{\phi_{k i}}{2}\left(\frac{I_{i t}}{K_{i t}}-\kappa_{i}\right)^{2}\right] K_{i t}^{\theta i}\left(Z_{i t} H_{i t}\right)^{1-\theta i} \geq I_{c t}+I_{i t}
$$

where the inputs - hours worked $\left(H_{c t}\right.$ and $\left.H_{i t}\right)$ and capital invested $\left(K_{c t}\right.$ and $\left.K_{i t}\right)$ - are combined in, respectively, the consumption and investment production functions at time t. $Z_{c t}$ and $Z_{i t}$ are sector-specific, labour-augmenting technology shocks, capturing the unobserved productivity dynamics. Note that aggregate investment is defined as the sum of the investment goods allocated in the consumption-good sector $\left(I_{c t}\right)$ and the investement goods bound to the same investment-good sector $\left(I_{i t}\right)$, so that $I_{t}=I_{c t}+I_{i t}$.

Quadratic adjustment cost functions are added in order to introduce some dynamics in the adjustment of the input demand to the equilibrium level. They are designed so that any change in the employment of either labour or capital translates into a cost, subtracting directly from the level of output. These costs arise both when shifting previously allocated resources across sectors and when employing new ones. The magnitude of the adjustment costs depends on the non-negative parameters $\phi_{h c}, \phi_{h i}, \phi_{k c}$ and $\phi_{k c}$; in order to have zero adjustment costs in equilibrium, the steady state value of $\eta_{c}, \eta_{i}, \kappa_{c}$ and $\kappa_{i}$ are set equal to the steady state growth rates of aggregated hours worked and investment.

The laws of motion of capital in the two sectors are

$$
\begin{gathered}
\left(1-\delta_{c}\right) K_{c t}+I_{c t} \geq K_{c t+1} \\
\left(1-\delta_{i}\right) K_{i t}+I_{i t} \geq K_{i t+1}
\end{gathered}
$$

where $\delta_{c}$ and $\delta_{i}$ are the depreciation rates, lying between 0 and 1 .

Finally, the model makes assumptions on the stochastic behaviour of the three driving processes, $A_{t}, Z_{c t}$ and $Z_{i t}$. Each shock can be decomposed into a part which is stationary in levels, called level component, and a part which is non stationary in levels, but stationary in growth rates, called growth rate component. Both these components follow an autoregressive process. The equations defining the shocks in this economy are

$$
\begin{gathered}
\ln \left(A_{t}\right)=\ln \left(a_{t}^{l}\right)+\ln \left(A_{t}^{g}\right) \\
\ln \left(a_{t}^{l}\right)=\rho_{a}^{l} \ln \left(a_{t-1}^{l}\right)+\varepsilon_{a t}^{l} \\
\ln \left(A_{t}^{g} / A_{t-1}^{g}\right)=\left(1-\rho_{a}^{g}\right) \ln \left(a^{g}\right)+\rho_{a}^{g} \ln \left(A_{t-1}^{g} / A_{t-2}^{g}\right)+\varepsilon_{a t}^{g} \\
\ln \left(Z_{c t}\right)=\ln \left(z_{c t}^{l}\right)+\ln \left(Z_{t}^{g}\right) \\
\ln \left(z_{c t}^{l}\right)=\rho_{c}^{l} \ln \left(z_{c t-1}^{l}\right)+\varepsilon_{c t}^{l}
\end{gathered}
$$




$$
\begin{gathered}
\ln \left(Z_{i t}\right)=\ln \left(z_{i t}^{l}\right)+\ln \left(Z_{t}^{g}\right) \\
\ln \left(z_{i t}^{l}\right)=\rho_{i}^{l} \ln \left(z_{i t-1}^{l}\right)+\varepsilon_{i t}^{l} \\
\ln \left(Z_{t}^{g} / Z_{t-1}^{g}\right)=\left(1-\rho^{g}\right) \ln \left(z^{g}\right)+\rho^{g} \ln \left(Z_{t-1}^{g} / Z_{t-2}^{g}\right)+\varepsilon_{t}^{g}
\end{gathered}
$$

All the autoregressive parameters lie between 0 and 1 and the innovations are serially, mutually uncorrelated and normally distributed, with zero mean and standard deviations given by $\sigma_{a}^{l}, \sigma_{a}^{g}, \sigma_{c}^{l}, \sigma_{i}^{l}, \sigma_{c}^{g}$. Note that $a^{g}$ is the long-run average growth rates of $A_{t}$, while $z^{g}$ is the long-run average growth rate of $Z_{c t}$ and $Z_{i t}$.

According to this specification, the driving processes are designed so that the model can take into account a variety of heterogeneous dynamics generally observed in macroeconomic variables, including non-stationary behaviours. Indeed, while both the level and the growth components impact on the level and growth rates of the corresponding shock in the short run, in the long run only the growth rate components are responsible for the non stationary behaviour of the key variables of the model - consumption, investment and hours worked. Moreover, this specification of the driving processes accounts for very flexible stochastic properties of each shock, according to the value assigned to the parameters. For instance, when $\rho^{g} \rightarrow 0$, the growth rate component of sectoral productivity becomes close to a random walk process, while when $\rho^{g} \rightarrow 1$, it is close to have two unit roots: this means that, the higher is $\rho^{g}$, the more persistent are the deviations of the non stationary processes from their long run average growth rate.

In light of our application, this means that the model can account for both transitory changes in the productivity patterns and very persistent shifts in its growth rate. However, the behaviour of productivity in the (very) long run is the same across sectors, implying that consumption and investment share the same stochastic trend, i.e. they are cointegrated, if non stationary. ${ }^{2}$

\subsection{Solving and estimating the model}

In this economy, the two welfare theorems apply, so either the Social Planner or the representative household's problem can be used to solve the model, i.e. find $C_{t}, H_{c t}, H_{i t}, I_{c t}$, $I_{i t}, K_{c t+1}, K_{i t+1}$ that maximize the utility function (1) subject to the technology (2)-(3) and capital accumulation (4)-(5) constraints, for all $t$.

The First Order Conditions (FOC) of this optimization problem, along with the aggregation constraints ${ }^{3}$ and the driving processes (6)-(13), form a system of non linear equations describing the behaviour of the variables of the model.

\footnotetext{
${ }^{2}$ As seen in the Introduction, this feature is required in order to take into account the observed behavior of the italian consumption and investment series over the last thirty years.

${ }^{3}$ See, respectively, equations (A.1)-(A.11) and (A.12)-(A.13) in the Appendix.
} 
However, the equilibrium deriving from this system is not stable, since the model allows the variables to grow at different rates, and some of them will be non stationary in the steady state. For this reason, we need to transform the variables into their stationarized counterparts, hereafter denoted by the corresponding lower-case letters. These variables correspond to the original ones, once they are divided by the source of non-stationarity the model assigns to them, so that in the steady state they are constant.

Following Ireland and Schuh (2008), the transformations for our key variables $-C_{t}, I_{t}$ and $H_{t}-$ are given by

$$
\begin{gathered}
c_{t}=\frac{C_{t}}{A_{t-1}^{g} Z_{t-1}^{g}} \\
h_{t}=\frac{H_{t}}{A_{t-1}^{g}} \\
i_{t}=\frac{I_{t}}{A_{t-1}^{g} Z_{t-1}^{g}}
\end{gathered}
$$

and their growth rates are defined as, respectively,

$$
\begin{gathered}
g_{t}^{c}=C_{t} / C_{t-1}=a_{t-1}^{g} z_{t-1}^{g}\left(c_{t} / c_{t-1}\right) \\
g_{t}^{i}=I_{t} / I_{t-1}=a_{t-1}^{g} z_{t-1}^{g}\left(i_{t} / i_{t-1}\right) \\
g_{t}^{h}=H_{t} / H_{t-1}=a_{t-1}^{g}\left(h_{t} / h_{t-1}\right)
\end{gathered}
$$

where $a_{t}^{g}$ is the stationarized counterpart of the growth rate component of the preference shock, given by $A_{t}^{g} / A_{t-1}^{g}$. Similarly, $z_{t}^{g}=Z_{t}^{g} / Z_{t-1}^{g}$. From (14)-(16), it is clear that, in the steady state, $H_{t}$ growth rate is

$$
g_{s s}^{h}=a^{g}
$$

while $C_{t}$ and $I_{t}$ grow at the same rate, given by

$$
g_{s s}^{c}=g_{s s}^{i}=a^{g} z^{g}
$$

The new, stable equilibrium can then be found solving the same system of equations as above, once the variables are substituted by their stationarized counterparts and equations (14)-(16) are added in order to keep track of the original observable key variables. This new set of equations needs to be log-linearized around the steady states of the stationarized variables, and the resulting system of linear expectational difference equations can be solved using standard methods. Sticking to the original paper, we will use Klein's (2000) method, based on the generalized Schur decomposition.

According to (17), the long-run average growth rate of hours worked is determined only by the preference shocks. However, the presence of a non-stationary component 
in the preference shocks implies that, in principle, the growth rate of hours worked can persistently shift. Though, intuitively, hours worked cannot grow over a certain threshold, given the limited nature of this variable, the non-stationary component is needed in order to capture the trend and non stationary features of this variable observed in real data.

The solved system can thus be written into its state-space form,

$$
\begin{aligned}
\mathbf{s}_{t+1} & =\mathbf{D} \mathbf{s}_{t}+\mathbf{F} \varepsilon_{t+1} \\
\mathbf{f}_{t} & =\mathbf{G} \mathbf{s}_{t}
\end{aligned}
$$

where $\mathbf{s}_{t}$ is a vector of possibly unobservable, state variables including the exogenous shocks of the model, while $\mathbf{f}_{t}$ is the vector of all those variables depending on $\mathbf{s}_{t}$, which includes the three observables of the model, $g_{c t}, g_{h t}$ and $g_{i t} ; \varepsilon_{t}$ is the vector of the innovations of the model.

Using this representation of the solution, we implicitly link the behaviour of three observable variables in $\mathbf{f}_{t}$, to a vector of unobservables, including the level and growth components of the shocks, so we can use the Kalman filter in order to estimate the structural parameters of the model ${ }^{4}$ by maximum likelihood and draw inference about the behaviour of the unobserved shocks to preferences and productivity.

\section{Empirical analysis}

The existing contributes on the italian productivity slowdown provide many evidences and stylized facts to understand the italian economic scenario over the last thirty years. 1995 markes a change in regime for output, employment and labour productivity growth: the abrupted slowdown of output growth comes along with a rising path of employment in the mid-1990s. The good performances of employment after decades of drag on growth have been related to the labour market reforms (Treu law in 1997; Biagi reform in 2003) that introduced some flexibility in the traditionally sticky hiring mechanisms, ${ }^{5}$ fostering the participation rates and increasing labour supply (Saltari and Travaglini, 2009). This may have contributed to the observed slowdown of labour productivity, reintroducing into jobs less productive workers (Sgherri, 2005) and determining the "growthless job creation" phenomenon (Boeri and Garibaldi, 2007).

At the same time, the contribution to growth from Total Factor Productivity (TFP) zeroed in the mid-1990s, and became negative after 2000 (Daveri and Jona-Lasinio, 2005; Orsi and Turino, 2010). This has generally been interpreted as an adverse productivity shock, reducing labour demand (Saltari and Travaglini, 2009), increasing the efficiency

\footnotetext{
${ }^{4}$ The model's parameters are: $\beta, \gamma, \theta_{c}, \theta_{i}, \phi_{h c}, \phi_{h i}, \phi_{k c}, \phi_{k i}, \eta_{c}, \eta_{i}, \kappa_{c}, \kappa_{i}, \delta_{c}, \delta_{i}, a^{g}, z^{g}, \rho_{a}^{l}, \rho_{a}^{g}, \rho_{c}^{l}, \rho^{g}$, $\rho_{i}^{l}, \sigma_{a}^{l}, \sigma_{a}^{g}, \sigma_{c}^{l}, \sigma^{g}, \sigma_{i}^{l}$.

${ }^{5}$ The part-time contract was introduced for the fist time in 1984. The "pacchetto Treu" in 1997 and the Biagi's reform in 2003 introduced and then increased the variety of fixed-term labour contracts.
} 
wedge (Orsi and Turino, 2010) and implying long-run shifts in the rate of technological progress (Sgherri, 2005) or of the technology frontier (Milana et al. 2008). Multisector growth accounting exercises and production function estimates show that the most important contribution to TFP drop came from Manufacturing (Bassanetti et al. 2004), especially from non durables (Daveri and Jona-Lasinio, 2005) and specific industries producing intermediate goods, like chemicals, pharmaceuticals and paper (Aiello et al. 2009). In general, the TFP drop seems to involve the main non-ICT industries and ICT producers (Venturini, 2004). The italian productivity drop in manufacturing in the late 1990s has also been related to factors affecting the technology catch-up (i.e. efficiency), like technology spillovers and bank ineffiency (Mastromarco and Zago, 2012).

Our work complements these evidences, using information on consumption, investment and hours worked in order to make inference on productivity, its persistency properties and its propagation mechanism in the economy. In a DSGE framework, it is possible to estimate to what extent preferences shocks may account for the observed behaviour of hours worked, also in light of the labour market reforms, and whether TFP dynamics may be explained by shocks to level and growth components of sectoral productivity.

The model is estimated using the quarterly series of italian consumption, investment and hours worked over the period 1981:1-2007:3, provided by ISTAT. More specifically, $C_{t}$ is proxied by final domestic household consumption expenditures, while $I_{t}$ is proxied by fixed gross domestic investment; both are expressed in millions of euros, chain-linked values, with reference year 2000, and exclude the farm sector. $H_{t}$ is given by the hours worked in the non farm sector. All the series are seasonally adjusted and normalized by the working age population. ${ }^{6}$ The growth rates of $C_{t}, I_{t}$ and $H_{t}$ are obtained as first difference of the logarithms of the corresponding level series. The main descriptive statistics of the key variables are reported in Table1. It is worth noting that consumption and investment grow at very similar average rate, as implied by the model, though investment is much more volatile than consumption about its long run trend.

Table 1: descriptive statistics key variables

\begin{tabular}{lcccc}
\hline \hline Variables & $C_{t}$ & $I_{t}$ & $H_{t}$ & $T F P_{t}$ \\
\hline mean & 0.0041 & 0.0043 & 0.0022 & 0.0079 \\
sd & 0.008 & 0.018 & 0.008 & 0.0161 \\
$1981-95$ & 0.0044 & 0.0034 & 0.0013 & 0.0135 \\
$1995-07$ & 0.0037 & 0.0054 & 0.0032 & 0.0013 \\
$2000-07$ & 0.0020 & 0.0051 & 0.0026 & 0.0016 \\
$2000-03$ & 0.0023 & 0.0066 & 0.0036 & -0.0026 \\
\hline \hline
\end{tabular}

Note: computations based on quarterly data (annual data for TFP)

Similarly to the specification estimated by Ireland and Schuh (2008), here we assume symmetric capital intensity across sectors $\left(\theta_{c}=\theta_{i}=\theta\right)$ and symmetric adjustment costs of

${ }^{6}$ We used the yearly data on the population aged between 15 and 65 . These data are provided by ISTAT. 
capital $\left(\phi_{k c}=\phi_{k i}=\phi_{k}\right)$ and labour $\left(\phi_{h c}=\phi_{h i}=\phi_{h}\right)$, applying these contraints throughout the estimation. Furthermore, we fix a priori the discount factor $\beta$ and the parameters governing the depreciation of capital, $\delta_{c}$ and $\delta_{i}$; for the former, we used the corresponding calibrated value in the literature, so that $\beta=0.99^{7}$; for the latter, we computed the value implied by the national series of capital and investment over the period 1981-2007, and so $\delta_{c}=\delta_{i}=0.010 .^{8}$ The parameters $\eta_{c}, \eta_{i}, \kappa_{c}, \kappa_{i}$ in the adjustment cost functions are defined so that they make the adjustment cost of capital and labour equal to zero in the steady-state.

On the other hand, differently from the original model, we fix also $\theta$ ex-ante, using the OECD data on labour income shares, so that $\theta=0.262 .{ }^{9}$ Indeed, in previous attempts to estimate the model, we found a very high capital share value, close to 0.70 . Moreover, our specification resulted better - in terms of the Akaike Information Criterion (AIC) than both the original specification, where $\theta$ is estimated under symmetry assumption across sectors, and an alternative scenario, where $\theta$ is estimated but left free to vary across sectors. ${ }^{10}$

\subsection{Results}

The results of the maximum likelihood estimation of the structural parameters are shown in Table $2 .{ }^{11}$

The model points at strong habit persistence in preferences, and this seems in line with various other evidences for Italy (e.g. Gruber, 2004; Belbute and Caleiro, 2010). Moreover, the cost of adjustment of labour $\left(\phi_{h}\right)$ is much higher than the one of capital $\left(\phi_{k}\right)$, at least in absolute terms. This would confirm the common view that the Italian labour market is not flexible, both for entering and for already allocated workers, and frictions to mobility

\footnotetext{
${ }^{7}$ This is quite a common choice in the literature (e.g. Chiarini and Piselli, 2005; Maffezzoli, 2000).

${ }^{8}$ We computed $\delta$ from the annual series of gross capital $\left(K_{t}\right)$ and investment $\left(I_{t}\right)$ in the non farm sector, provided by ISTAT, using the steady-state property of the aggregate law of motion of capital, given by the sum of the equations (4) and (5), so that

$$
\frac{I_{s s}}{K_{s s}}=\delta
$$

The annual depreciation rate, obtained as the average of the ratio $I / K$ over the period 1981-2007, is then converted into the corresponding quarterly value.

${ }^{9}$ We first computed the (simple) average of labour income shares (let us say, $\alpha$ ) for the period 1981-2007; the average capital income share is derived as $1-\alpha$, exploiting the property of a Cobb-Douglas function with constant returns to scale.

${ }^{10}$ The results of these alternative specifications are available upon request.

${ }^{11}$ Throughout the estimation, both the theoretical and the symmetry conditions have been imposed. The standard errors of the parameters have been computed using the same parametric procedure described in Ireland and Schuh's (2008) paper. This consists of estimating the model and simulating it 1000 times in order to obtain 1000 samples of artificial data for $C_{t}, I_{t}$ and $H_{t}$. The model parameters are then estimated again, using these datasets, and the standard error are computed as standard deviations of the resulting parameters.
} 
of labour are not negligible. Indeed, Italy is usually counted as a country where strict labour market regulations make it difficult and expensive for firms to adjust their demand to the optimal level of employment. ${ }^{12}$ At the same time, the high standard errors of these two parameters reveal that our estimates are much imprecise. Especially for $\phi_{h}$, this may be justified in light of the structural change in flexibility, introduced by the labour market reforms occurring in the time span considered in our analysis, as supported by other empirical evidences (e.g., Pacelli 2002).

\begin{tabular}{ccc} 
Table 2: Maximum Likelihood estimates and standard errors \\
\hline \hline Parameter & Estimate & Standard Error \\
\hline$\gamma$ & 0.8761 & 0.0796 \\
$\phi_{k}$ & 9.2181 & 40.4532 \\
$\phi_{h}$ & 65.1383 & 29.0017 \\
$a^{g}$ & 1.0018 & 0.0002 \\
$z^{g}$ & 1.0022 & 0.0010 \\
$\rho_{a}^{l}$ & 0.0000 & 0.0641 \\
$\sigma_{a}^{l}$ & 0.9247 & 0.3851 \\
$\rho_{a}^{g}$ & - & - \\
$\sigma_{a}^{g}$ & 0.0000 & 0.0011 \\
$\rho_{c}^{l}$ & 0.0000 & 0.1765 \\
$\sigma_{c}^{l}$ & 0.0068 & 0.0011 \\
$\rho^{g}$ & 0.5260 & 0.2286 \\
$\sigma^{g}$ & 0.0054 & 0.0017 \\
$\rho_{i}^{l}$ & 0.9405 & 0.0743 \\
$\sigma_{i}^{l}$ & 0.0199 & 0.0017 \\
\hline \hline log likelihood: 1025.53 & & \\
AIC: -2021.06 & & \\
& &
\end{tabular}

The remaining parameters govern the dynamics of the preference and productivity shocks driving our economy. As seen in the previous paragraph, $a^{g}$ and $z^{g}$ are linked to the steady state growth rates of the key variables through equations (17) and (18). In particular, $a^{g}$ represents the steady state growth rate of hours worked; our estimate is lower than the average growth rate of the hours worked series observed in our sample (see Table 1). However, when combining the estimated $a^{g}$ and $z^{g}$ into (18), the growth rate of consumption and investment implied by the estimation is 1.0041, matching almost perfectly the observed growth rate of these two variables. $z^{g}$ represents the average growth rate of productivity across sectors.

The level component of $A_{t}$ is a highly volatile white noise $\left(\rho_{a}^{l}=0.0000 ; \sigma_{a}^{l}=0.9247\right)$, while the growth rate component is not identified, due to $\sigma_{a}^{g}=0.0000$. This means that the model does not point at highly persistent preference shifts and, as a consequence, the

\footnotetext{
${ }^{12}$ See for instance Del Boca and Rota (1998), Pacelli (2002) and Rota (2001).
} 
growth rate of hours worked does not deviate from its long run average. This result implies that, if we interpret the preference shocks as shifters of labour supply, due for instance to labour market reforms, as in Saltari and Travaglini (2009), according to our model their effects on hours worked are extremely temporary, and the hypothesis of a long-run effect of structural reforms on employment is not verified.

Focusing on the parameters characterizing $Z_{c t}$ and $Z_{i t}$, there are some important differences in the driving processes of productivity across sectors. Indeed, though both share a highly persistent growth rate component $-\rho^{g}=0.5260, \sigma^{g}=0.0054-$ the level component of $Z_{c t}$ is a white-noise $-\rho_{c}^{l}=0.0000, \sigma_{c}^{l}=0.0068$ - while it is very close to a unit root in $Z_{i t}-\rho_{i}^{l}=0.9405, \sigma_{i}^{l}=0.0199$ - translating to a competitive driver in the long-run.

This picture is confirmed when looking at the relative importance of the shocks in explaining the behaviour of the key variables of the model, measured by the Forecast Error Variance (FEV) decompositions shown in Table 3.

Table 3: Forecast Error Variance Decompositions (\%)

\begin{tabular}{cccccc}
\hline \hline Quarters Ahead & $\varepsilon_{a}^{l}$ & $\varepsilon_{a}^{g}$ & $\varepsilon_{c}^{l}$ & $\varepsilon_{i}^{l}$ & $\varepsilon^{g}$ \\
\hline Consumption & & & & & \\
1 & 53.7 & 0.0 & 27.1 & 0.0 & 19.2 \\
4 & 41.9 & 0.0 & 6.7 & 0.0 & 51.4 \\
8 & 29.1 & 0.0 & 3.1 & 0.0 & 67.9 \\
12 & 21.7 & 0.0 & 1.9 & 0.0 & 76.3 \\
20 & 13.5 & 0.0 & 1.1 & 0.1 & 85.2 \\
40 & 6.0 & 0.0 & 0.4 & 0.7 & 92.9 \\
\hline Investment & & & & & \\
1 & 17.0 & 0.0 & 0.0 & 76.8 & 6.2 \\
4 & 12.9 & 0.0 & 0.2 & 68.2 & 18.7 \\
8 & 10.0 & 0.0 & 0.1 & 65.5 & 27.3 \\
12 & 8.30 & 0.0 & 0.1 & 58.4 & 33.3 \\
20 & 6.00 & 0.0 & 0.1 & 50.9 & 43.0 \\
40 & 3.50 & 0.0 & 0.0 & 35.3 & 61.2 \\
\hline 1 & & & & & \\
4 & 93.0 & 0.0 & 5.0 & 0.1 & 1.9 \\
8 & 93.9 & 0.0 & 1.6 & 0.5 & 4.1 \\
40 & 93.5 & 0.0 & 1.0 & 1.4 & 4.1 \\
\hline \hline Hours worked & 92.9 & 0.0 & 0.9 & 2.7 & 3.5 \\
12 & 90.7 & 0.0 & 0.7 & 5.0 & 3.6 \\
44.2 & 0.0 & 0.7 & 6.6 & 8.5 \\
\hline \hline
\end{tabular}

As expected, the growth component jointly determines the bulk of the variability of $C_{t}$ and $I_{t}$ in the long run. However, the level component is still an important competitor of the growth component for investment, explaining relevant shares of the variance of $I_{t}$ for 
all the forecast horizons. The level component of $A_{t}$ is the main driver of hours worked in the long run, but it is also not negligible for the very short run dynamics - up to 4 quarters - of consumption, due to the direct effect that preference shocks have on consumption decisions through the utility function.

Looking at the IRFs of the three key variables to the level and growth components of each shock (Figures 2a-c), it results that shocks to preferences are identified as having temporary and synchronized effects on all three variables; moreover, shocks to the level component of consumption-specific technology have higher though temporary effects on consumption, and much smaller effects on hours worked and investment. On the other hand, the level component of the investment-specific shock has a permanent small effect on consumption and a highly persistent impact on investment: the model predicts that it may be a long-run competitor of the common technology shock across sectors, which in turn has a permanent effect on both consumption and investment, and leaves hours worked almost unchanged in the long run.

Taking one step forward, we now discuss the behaviour of productivity in each sector in light of the existing evidences on the italian slowdown. To this purpose, the smoothed estimates of $Z_{c t}$ and $Z_{i t}$, decomposed into the contribution of the stationary and non stationary components, have been computed and plotted in Figure 3.

At first sight, the model does not reproduce the slowdown of productivity observed in actual data from 1995: if we exclude the period 1995-1997 for $Z_{c t}$ (panel 2) and 1995:41997:2 for $Z_{i t}$ (panel 3), productivity is growing in both sectors, at least until 2000. At the same time, this result indirectly stresses the important role played by specific, non durable intermediates, like chemicals, paper and pharmaceuticals, whose contribution to the productivity decline in Italy in the last portion of the 1990s has been assessed in different empirical analysis (e.g., Daveri and Jona-Lasinio, 2005; Aiello et al., 2009). Indeed, intermediate goods are mainly employed in the production process and are excluded de facto from the consumption aggregate used here for the estimation.

Furthermore, the growth of productivity in the consumption and investment-good sector seems to account for the high and positive contribution to TFP growth caming from some durables in the second half of the 1990s, in particular some high tech industries producing electrical and optical equipments (Daveri and Jona-Lasinio, 2005). In light of our two-sector disaggregation, part of these productions - like personal computers and mobile phones - are included in the consumption-good sector, while machineries and equipments bound to the production process are encompassed in the investment-good sector. Finally, the growing path of $Z_{c t}$ is also consistent with the exceptionally positive growth of TFP observed in the financial sector during the internet bubble years, 1995-2000 (Daveri and Jona-Lasinio, 2005).

Moving to the post-2000 portion of the productivity series, we do observe a marked drop in the consumption-specific productivity, due to the shared growth component (Figure 3 , panel 2). This reproduces quite well the sharp drop in the productivity of both durables and non durables, documented by Daveri and Jona-Lasinio (2005): TFP in the durables 
productions grew at a high rate in the second half of the 1990s and fell abruptly in the first years of the 2000s, in particular in the production of electrical and optical equipments, which include also goods bound to households' consumption. At the mean time, also the non durable productions contributed negatively to TFP growth after 2000, though in some of these industries the decline started before 2000. Note that non durables include the bulk of the Made in Italy productions - textile, clothing, leather and furniture - in addition to the intermediate goods, that however are not considered in this analysis.

While productivity in the consumption-good sector follows this declining path after 2000, we do not observe a similar path in the investment-good sector: looking at Figure 3 (panel 3), sectoral productivity seems to stick to its long run trend, and no change in regime is observed, excepted for a slight slowdown in $Z_{i t}$ between 2002-2003 (panel 6). This is in line with the observation that, after 2004, italian growth has been driven by few sectors, including the instrumental mechanical (ISTAT, 2010), whose productions are mainly bound to other industries. However, the not-declining behaviour of investment-good productivity relies on its growing level component, which somehow balanced the declining path of the shared growth component, especially after 2003. With respect to this, the decline of the investment-good sector relies on the persistency properties of this level component.

This point is confirmed looking at the counterfactuals, i.e. the simulated series of consumption, investment and hours worked when we zero out the effect of each shock over the observed period. Focusing on panel 11 in Figure 4, it is clear that the model assigns an important role to the level component of the investment-specific productivity shocks, since otherwise we would have observed a declining path for $I_{t}$ after 2000 .

\section{Conclusions}

This work studies the structural relations between the italian weak macroeconomic performances and its productivity dynamics, using a DSGE approach, as in the bulk of the US literature. Modifying Ireland and Schuh's (2008) two-sector RBC model in order to account for the italian peculiarities, we interpret the last fifteen years of unsatisfactory italian economic dynamics in light of a permanent negative shock to the common component of productivity across sectors. The growing path of hours worked during the 1990s and the first part of the 2000s is interpreted as arising from a temporary shock to preferences, driven by the labour market reforms over that period. This unified theoretical framework tries to reconcile the supply-side evidences on productivity patterns with the demand-side dynamics of consumption and investment, differently from the bulk of the existing literature on italian productivity slowdown, mainly based on partial equilbrium and supply-side oriented analysis.

The rich specification of the shocks in this model allows us to infer the sources of short and long-run growth of productivity in each sector and relate the observed italian productivity slowdown over the last 15 years to the performances of each sector. In general, 
our findings point at a shared decline in the consumption and investement-good sectoral productivity, though the decline after 2000 is not observable in the investment-good sector, due to the balancing effect of its level component. This implies that the quite common view that the bulk of the productivity problems in Italy stems only from the most traditional sectors - the consumption-good sector, whose productions are close, though not perfectly, to the made in Italy specializations - is only partially confirmed. Indeed, the starting point of the decline in the investment good sector relies on the persistency properties of its productivity level component, which is interpreted as an important long run-competitor of the common growth component. Moreover, not reproducing the slowdown observed in the mid-1990s, the model provides an indirect proof that the intermediate-good productions played a fundamental role.

Since derived from a general equilibrium framework, these results provide useful insights into the italian productivity slowdown. In particular, the weakness of the consumptiongood sector is an alternative way of describing the loss of competitiveness in the main made in Italy production sectors, which represent the structure of the italian productivity systerm. With respect to this, the italian productivity slowdown and the weakness of consumption should not be considered as completely independent phenomena, since the decline of productivity in the largest economic sector may have produced real negative effects on consumption, through the negative effects on wages. Telling it in Mario Draghi's words: "Productivity is the key variable. (...) Restoring a rapidly rising path of productivity will solve the Italian economy's supply problem, permit wage increases and strengthen domestic demand."13

\section{References}

[1] Aiello, F., Mastromarco, C., Zago, A. (2011), "Be productive or face decline. On the sources and determinants of output growth in Italian manufacturing firms", Empirical Economics 41 (3), 787-815.

[2] Aiello, F., V. Pupo and F. Ricotta (2009), "Sulla Dinamica della Produttività Totale dei Fattori in Italia: un'analisi settoriale", Rivista di Economia e Politica Industriale, No 3, 413-436.

[3] Bassanetti, A., M. Iommi, C. Jona-Lasinio and F. Zollino (2004), "La crescita dell'economia italiana negli anni novanta tra ritardo tecnologico e rallentamento della produttività", Bank of Italy, Economic Research Department, Temi di discussione, No 539, December 2004.

[4] Belbute, J.M. and A. Caleiro (2010), "Cross Country Evidence on Consumption Persistence", MPRA Paper No. 22008.

\footnotetext{
${ }^{13}$ from Mario Draghi's 2007 speech as former Governor of the Bank of Italy.
} 
[5] Boeri, T., and P. Garibaldi (2007), "Two Tier Reforms of Employment protection: a honeymoon effect?", Economic Journal, Royal Economic Society, vol.117(521), pages $357-385,06$.

[6] Chiarini B. and P. Piselli (2005), "Business cycle, unemployment benefits and productivity shocks", Journal of Macroeconomics, vol. 27, No. 4, 670-690.

[7] Daveri, F., and C. Jona-Lasinio (2005), "Italy's Decline: Getting the Facts Right", (December 2005). IGIER Working Paper No.301, available at SSRN: http://ssrn.com/abstract=871039 or http://dx.doi.org/10.2139/ssrn.871039

[8] Del Boca A. and P. Rota (1998), "How much does hiring and firing cost? Survey evidence from a sample of Italian firms", Labour vol. 12, 427-449.

[9] Greenwood, J., Hercowitz, Z., Krusell, P. (2000), "The role of investment-specific technological change in the business cycle", European Economic Review 44, 91-115.

[10] Greenwood, J., Hercowitz, Z., Krusell, P. (1997), "Long-run implications of investment-specific technological change", American Economic Review 87, 342-362.

[11] Gruber, J.W. (2004), "A present value test of habits and the current account", Journal of Monetary Economics, vol. 51, No. 7, 1495-1507.

[12] Hamilton, J.D. (1994), "Time Series Analysis", Princeton University Press.

[13] Hansen, G.D. (1985), "Indivisible labour and the business cycle", Journal of Monetary Economics 16 (1985), 309-327, North Holland.

[14] Ireland, P.N. (2011), "Stochastic Growth in the United States and Euro Area", NBER Working Papers 16681, National Bureau of Economic Research, Inc.

[15] Ireland, P.N., Schuh, S. (2008), "Productivity and US macroeconomic performance: Interpreting the past and predicting the future with a two-sector real business cycle model", Review of Economic Dynamics, 11 (2008), 473-492.

[16] Istituto Nazionale di Statistica ISTAT (2010), "Rapporto Annuale", Rome.

[17] Justiniano, A., Primiceri, G. E., Tambalotti, A. (2011), "Investment shocks and the relative price of investment", Review of Economic Dynamics, 14(1), 102-121.

[18] Justiniano, A., Primiceri, G. E., Tambalotti, A. (2010), "Investment shocks and business cycles", Journal of Monetary Economics, 57(2), 132-145.

[19] King, R. G., Plosser, C. I., Rebelo, S. T. (1988), "Production, growth and business cycles: II. New directions", Journal of Monetary Economics, Elsevier, vol. 21(2-3), pages 309-341. 
[20] Kydland, Finn E \& Prescott, Edward C (1982), "Time to Build and Aggregate Fluctuations", Econometrica, Econometric Society, vol. 50(6), pages 1345-70, November.

[21] Klein, P. (2000), "Using the generalized Schur form to solve a multivariate linear rational expectation model", Journal of Economic Dynamics and Control 24, 14051423 .

[22] Maffezzoli, M. (2000), "Non-Walrasian Labor Markets and Real Business Cycles", IGIER working paper No. 167.

[23] Mastromarco, C., Zago, A. (2012), "On modelling the determinants of TFP growth", Structural Change and Economic Dynamics, Elsevier, vol. 23(4), pages 373-382.

[24] Milana, C., Leopoldo, N., Zeli, A. (2008), "Changes in Multifactor Productivity in Italy from 1998-2004: Evidence from Firm-Level Data Using DEA", EU-KLEMS Working paper, (33).

[25] Orsi, R., and F. Turino (2010), "The last fifteen years of stagnation in Italy: A Business Cycle Accounting Perspective", Dipartimento Scienze Economiche, Universita' di Bologna, Working Paper 707.

[26] Pacelli, L. (2002), "Fixed Term Contracts, Social Security Rebates and Labour Demand in Italy", LABORatorio R. Revelli Working Papers Series No.7.

[27] Pakko, M.R. (2005), "Changing technology trends, transition dynamics, and growth accounting", in: Contributions to Macroeconomics, vol. 5. Article 12.

[28] Pakko, M.R. (2002), "What happens when the technology growth trend changes? Transition dynamics, capital growth, and the "New Economy", Review of Economic Dynamics 5, 376-407.

[29] Park, W. (2012), "Cointegrated Sectoral Productivities and InvestmentSpecific Technology in U.S. Business Cycles", December 24, 2012, University of Colorado at Boulder, Economics Department Paper, available at SSRN: http://ssrn.com/abstract=2173566 or http://dx.doi.org/10.2139/ssrn.2173566

[30] Rota, P. (2001), "Dynamic Labour Demand with Lumpy and Kinked Adjustment Costs", Fondazione Eni Enrico Mattei, Nota di Lavoro No. 20.

[31] Saltari, E., and G. Travaglini (2009), "The Productivity Slowdown Puzzle. Technological and Non-technological Shocks in the Labor Market", International Economic Journal, 23: 4, 483 - 509 .

[32] Schmitt-Grohe, S., Uribe, M. (2011), "Business Cycles With A Common Trend in Neutral and Investment-Specific Productivity", Review of Economic Dynamics, Elsevier for the Society for Economic Dynamics. Volume 14, Issue 1. (January 2011). 
[33] Sgherri, S. (2005), "Long-run productivity shifts and cyclical fluctuations: evidence from Italy", IMF WP/05/228.

[34] van Ark, B., O’Mahony, M., Ypma, G. (Eds.) (2007), "THE EU KLEMS PRODUCTIVITY REPORT", WP2007-1 Policy Support and Anticipating Scientific and Technological Neeeds, European Commision.

[35] Venturini, F. (2004), "The determinants of Italian slowdown: what do the data say", EPKE working paper $\mathrm{n}^{\circ} 29$, NIESR, London.

[36] Whelan, K. (2003), "A two-sector approach to modelling US NIPA data", Journal of Money, Credit and Banking 35, 627-656. 


\section{Appendix}

\section{A Equilibrium conditions in the common-trend model}

The Social Planner's problem consists of choosing

$$
\left\{C_{t}, H_{c t}, H_{i t}, I_{c t}, I_{i t}, K_{c t+1}, K_{i t+1}\right\} \forall t
$$

so that the social utility function is maximized, subject to the production and capital accumulation constraints. Denote by $\Lambda_{c t}$ and $\Lambda_{i t}$ the non-negative Lagrange multipliers on the technology contraints (2)-(3), and by $\Xi_{c t}$ and $\Xi_{i t}$ the non-negative Lagrange multipliers on the capital accumulation constraints (4)-(5), then the First Order Conditions (FOC) derived from the Lagrangian of the planner's problem are given by 


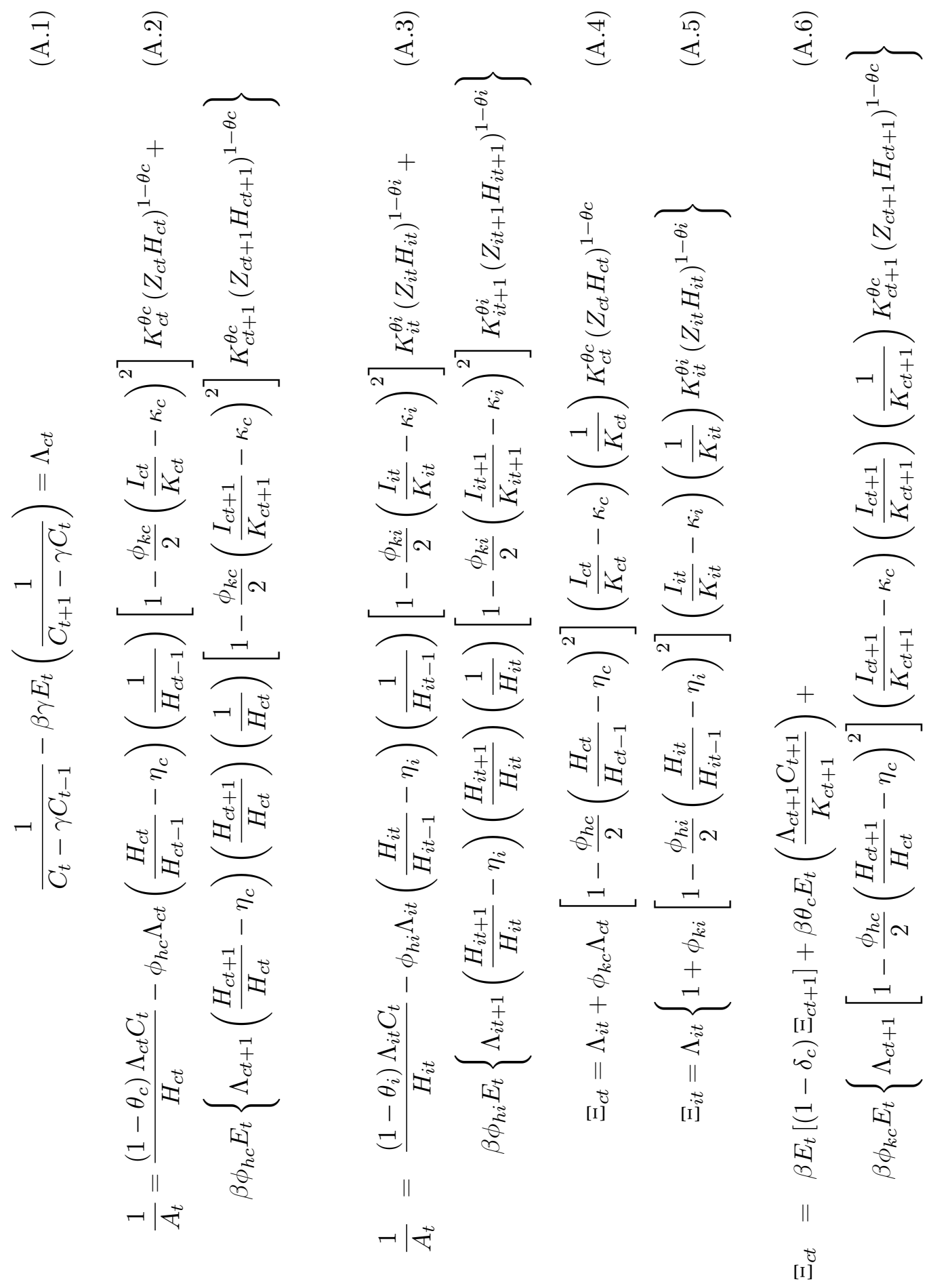




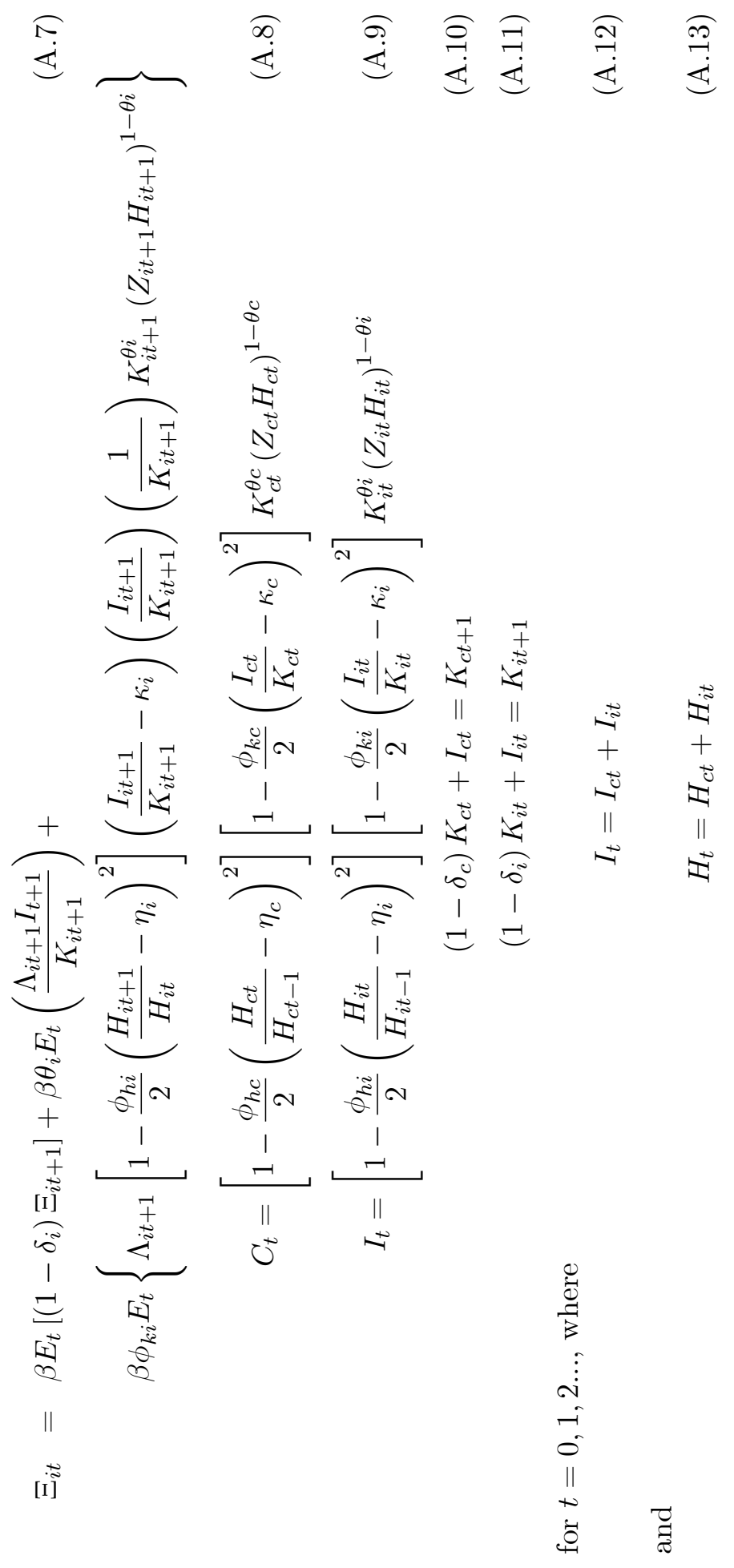


The first order conditions A.1-A.11, along with the aggregation constraints A.12-A.13 and the driving processes, as specified in (6)-(13) in the main text, are the equilibrium conditions of the model. This is a system of 21 equations in 21 variables $-C_{t}, H_{t}, H_{c t}, H_{i t}$, $I_{t}, K_{c t}, K_{i t}, \Lambda_{c t}, \Lambda_{i t}, \Xi_{c t}, \Xi_{i t}, A_{t}, a_{t}^{l}, A_{t}^{g}, Z_{c t}, z_{c t}^{l}, Z_{i t}, z_{i t}^{l}$ and $Z_{t}^{g}$. However, the equilibrium deriving from the solution of this system is not stable, since variables grow and some of them also may also be non stationary. Following Ireland and Schuh (2008), this system can then be written in terms of the stationarized variables, i.e. variables that are constant in the steady state, obtained dividing the original ones by the sources of non-stationarity assigned to them by the model, so that

$$
\begin{gathered}
c_{t}=C_{t} /\left(A_{t-1}^{g} Z_{t-1}^{g}\right) \\
h_{t}=H_{t} / A_{t-1}^{g} \\
h_{c t}=H_{c t} / A_{t-1}^{g} \\
h_{i t}=H_{i t} / A_{t-1}^{g} \\
i_{t}=I_{t} /\left(A_{t-1}^{g} Z_{t-1}^{g}\right) \\
i_{c t}=I_{c t} /\left(A_{t-1}^{g} Z_{t-1}^{g}\right) \\
i_{i t}=I_{i t} /\left(A_{t-1}^{g} Z_{i-1}^{g}\right) \\
k_{c t}=K_{c t} /\left(A_{t-1}^{g} Z_{t-1}^{g}\right) \\
k_{i t}=K_{i t} /\left(A_{t-1}^{g} Z_{t-1}^{g}\right) \\
\lambda_{c t}=A_{t-1}^{g} Z_{t-1}^{g} \Lambda_{c t} \\
\lambda_{i t}=A_{t-1}^{g} Z_{t-1}^{g} \Lambda_{i t} \\
\xi_{c t}=A_{t-1}^{g} Z_{t-1}^{g} \Xi_{c t} \\
\xi_{i t}=A_{t-1}^{g} Z_{t-1}^{g} \Xi_{i t} \\
a_{t}=A_{t} / A_{t-1}^{g} \\
a_{t}^{g}=A_{t}^{g} / A_{t-1}^{g} \\
z_{c t}=Z_{c t} / Z_{t-1}^{g} \\
z_{i t}=Z_{i t} / Z_{i t-1}^{g} \\
z_{t}^{g}=Z_{t}^{g} / Z_{t-1}^{g}
\end{gathered}
$$

while $a_{t}^{l}, z_{c t}^{l}, z_{i t}^{l}$ remain the same, since already stable. The new system is obtained substituting the original variables with their stationary counterparts; however, in order to keep track of the three key original variables, $C_{t}, H_{t}$ and $I_{t}$, which are our observables, 
we need to introduce three further variables, $g_{t}^{c}, g_{t}^{i}$ and $g_{t}^{h}$, corresponding to their growth rates and defined as

$$
\begin{gathered}
g_{t}^{c}=C_{t} / C_{t-1}=a_{t-1}^{g} z_{t-1}^{g}\left(c_{t} / c_{t-1}\right) \\
g_{t}^{i}=I_{t} / I_{t-1}=a_{t-1}^{g} z_{t-1}^{g}\left(i_{t} / i_{t-1}\right) \\
g_{t}^{h}=H_{t} / H_{t-1}=a_{t-1}^{g}\left(h_{t} / h_{t-1}\right)
\end{gathered}
$$

The final system consists of 24 equations in 24 variables, and can be log-linearized around the steady state of the lower-case variables and solved using Klein's (2000) method. 


\section{B Graphs}

Figure 1a: per capita real consumption and investments (logs), chained 2000 euros, 1981.1-2007.3

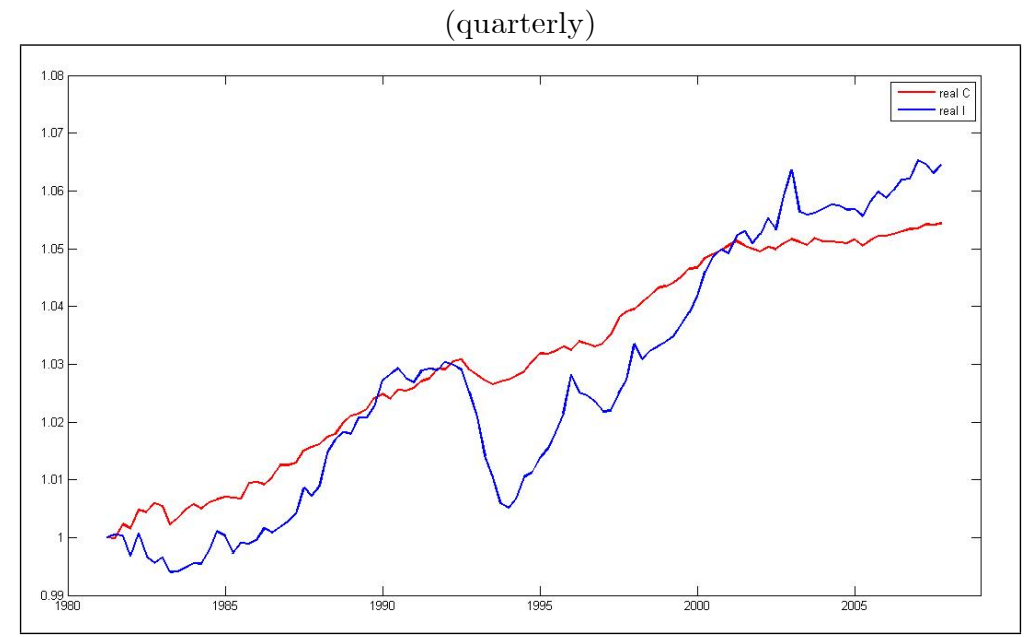

Figure 1b: Total Factor Productivity (logs), based on Value Added, 2000=100, 1981-2007 (yearly)

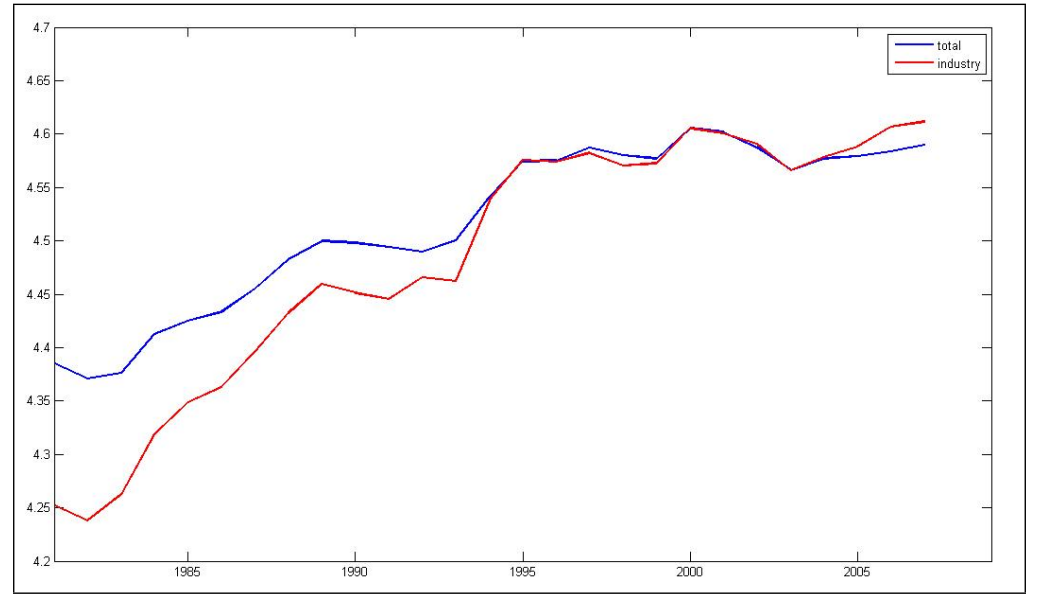




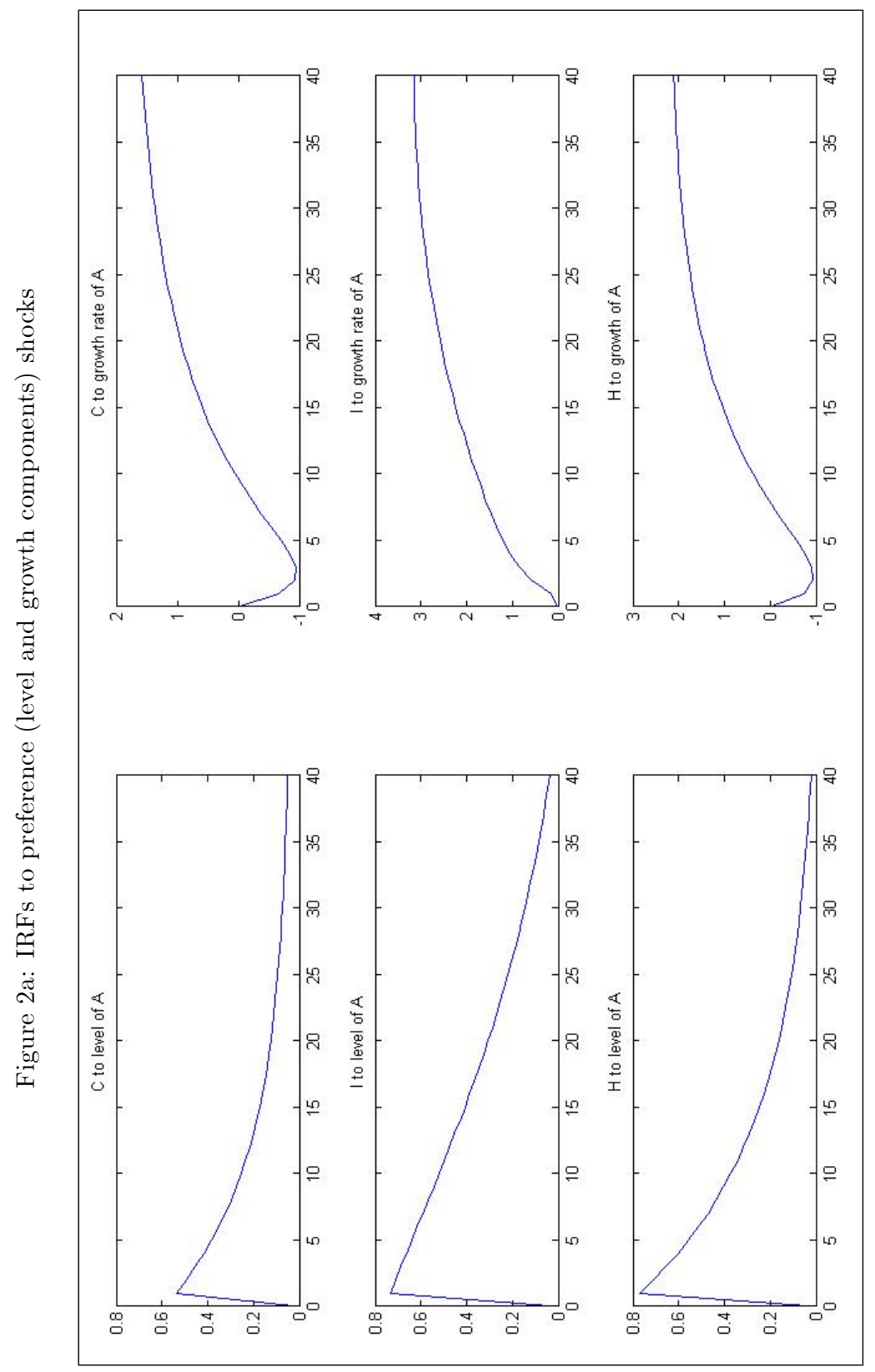




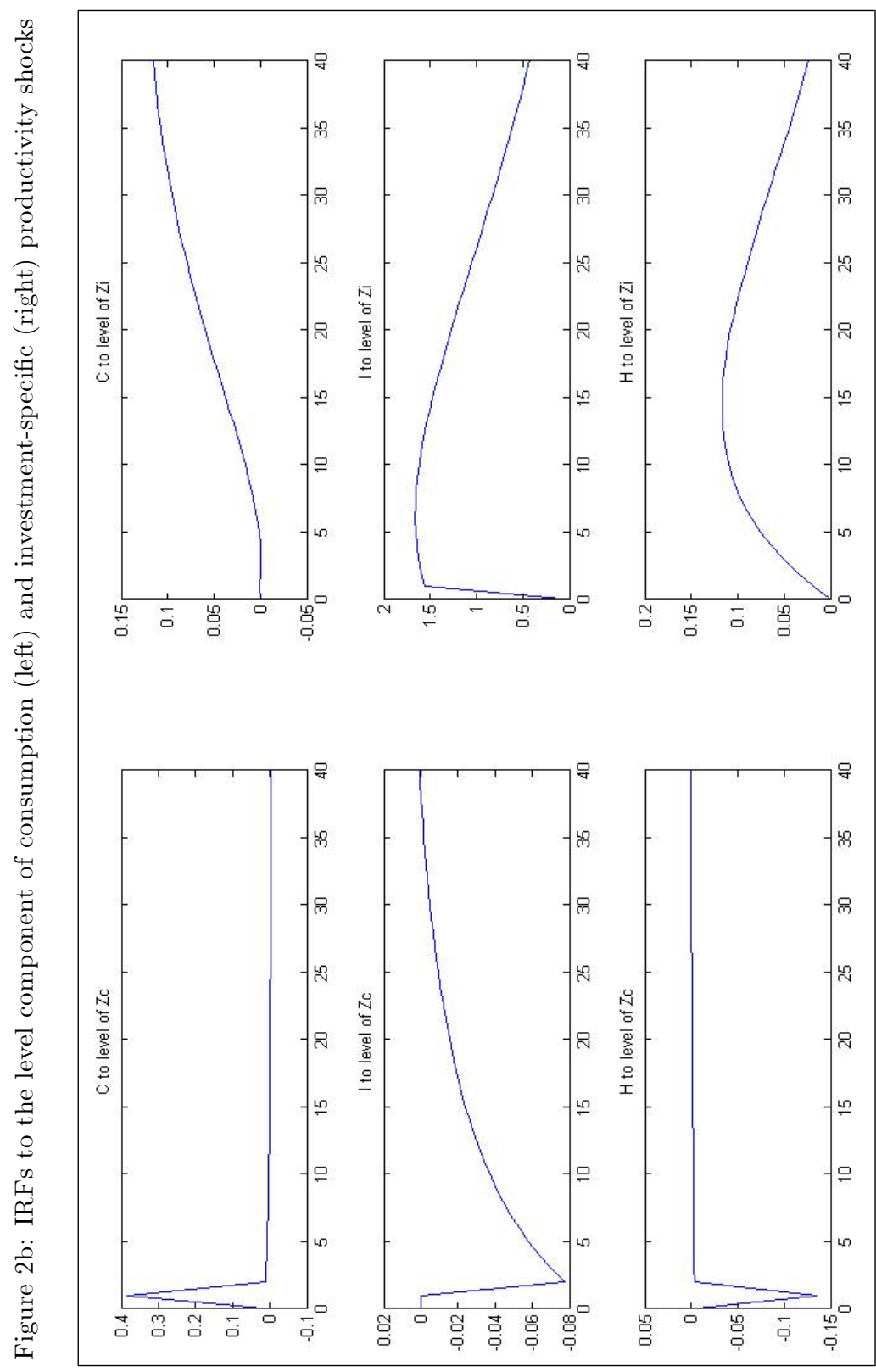


Figure 2c: IRFs to the common growth component of productivity shocks

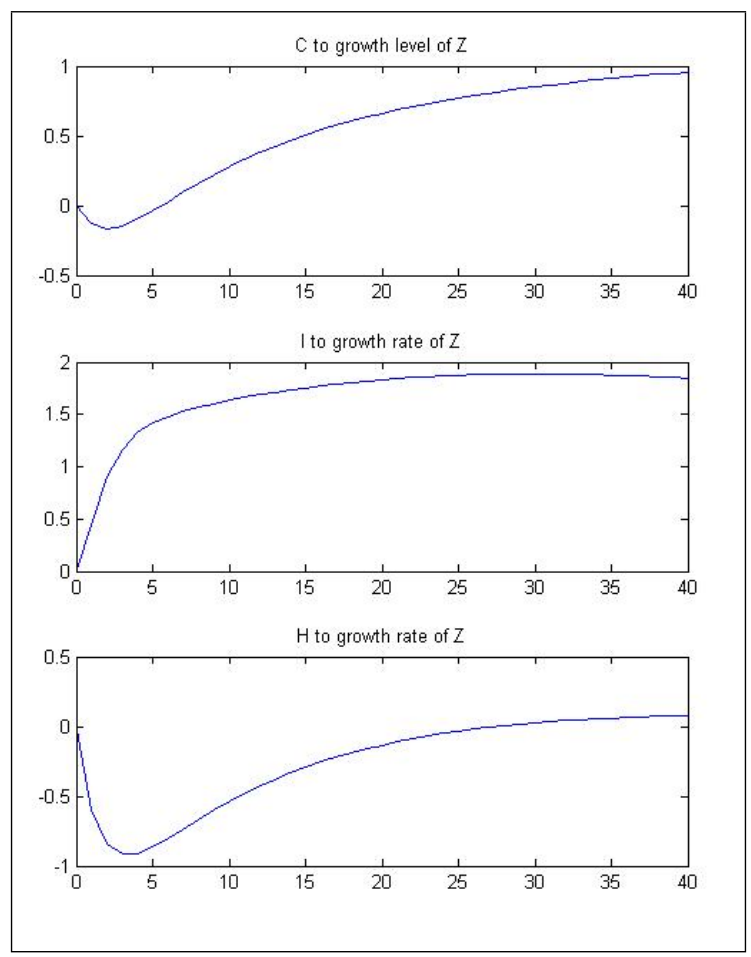




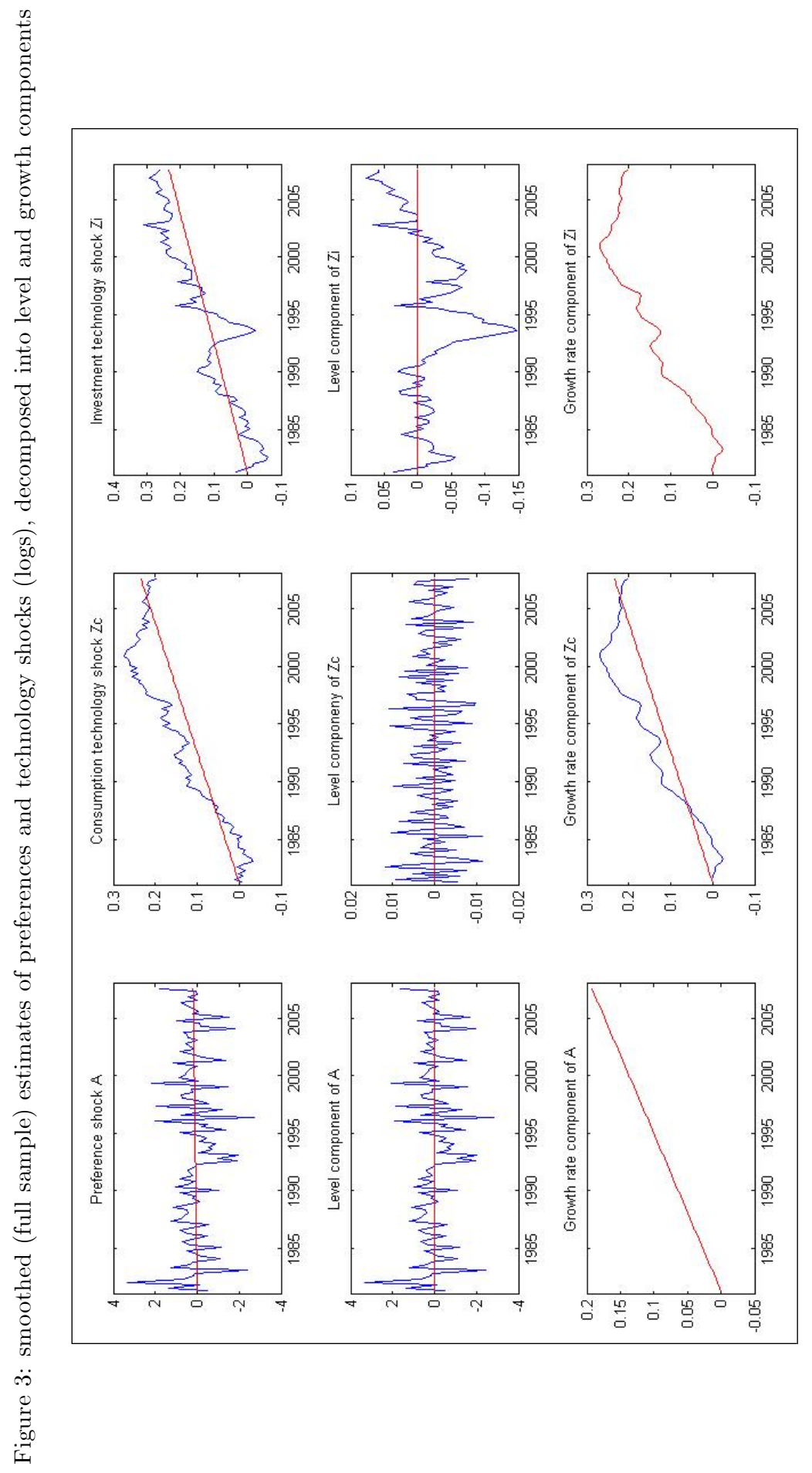




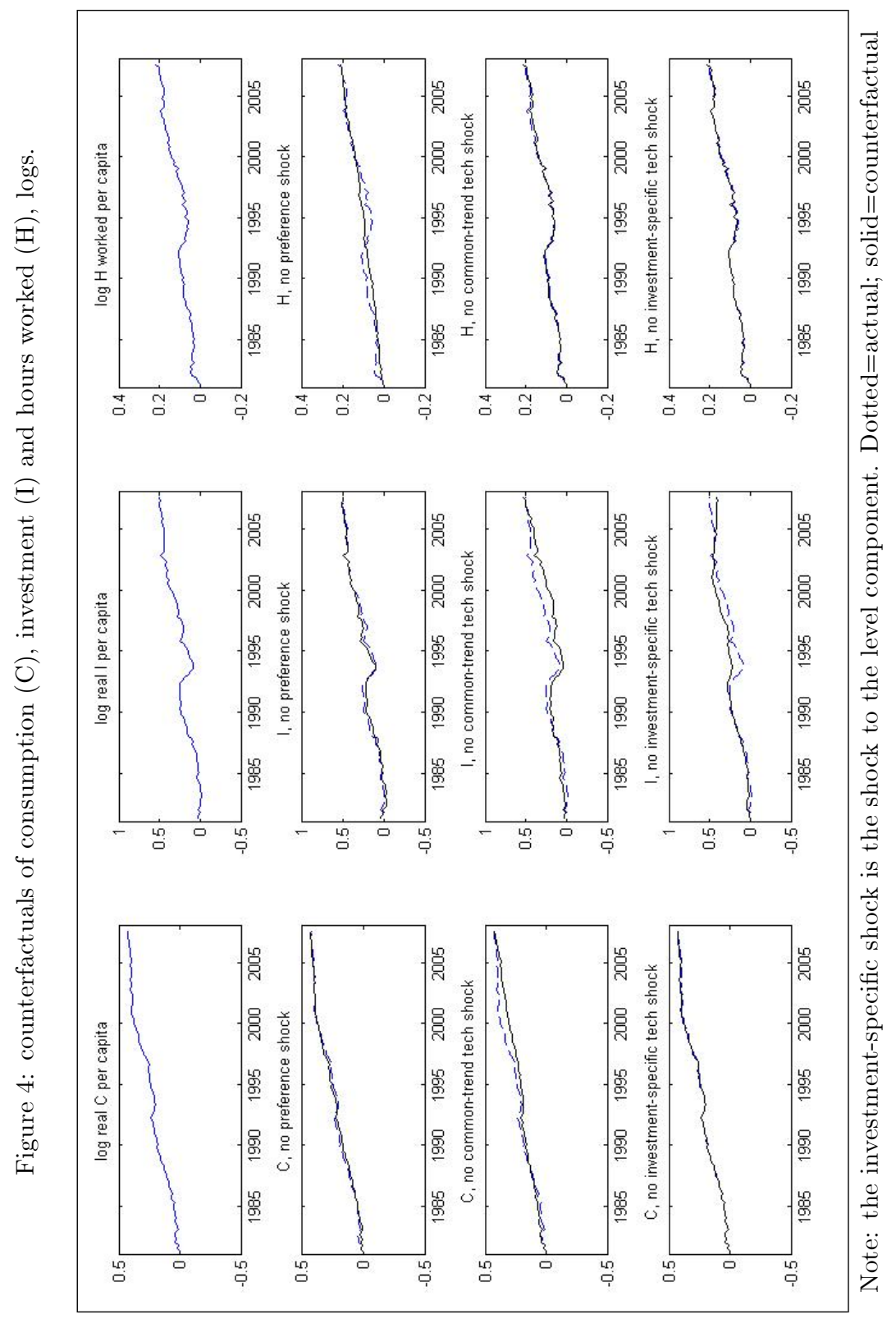

